\title{
QUALIDADE DE SEMENTES DE SORGO (Sorghum bicolor L.) CONFORME A SUA LOCALIZAÇÃO NO SECADOR DE LEITO FIXO COM DISTRIBUIÇÃO RADIAL DE AR
}

\author{
José Cardoso Sobrinho ${ }^{1}$, Jadir Nogueira da Silva ${ }^{2}$, Paulo Cesar Corrêa ${ }^{3}$ \\ e Denise Cunha Fernandes dos Santos Dias ${ }^{4}$
}

\begin{abstract}
RESUMO
Desenvolveu-se um estudo acerca da qualidade fisiológica de sementes de sorgo variedade BR 601 secadas, num secador estacionário, tipo "tubo central perfurado". Foram estudadas três alturas combinadas com quatro distâncias em relação ao duto central, perfazendo-se o total de 12 tratamentos. Observou-se que, em geral, as amostras de sementes situadas a $0,10 \mathrm{~m}$ do duto de ar quente apresentavam teor de umidade inferior ao da amostra geral, a testemunha. Não se verilicaram, nos testes de qualidade, diferenças significativas pelo teste $\mathrm{F}$, a $5 \%$ de probabilidade, quando se comparou a qualidade das sementes coletadas em distintos locais com a amostra geral.
\end{abstract}

Palavras-chave: secagem, qualidade, sementes

\section{SORGHUM (Sorghum bicolor L.) SEED QUALITY ACCORDING TO ITS LOCALIZATION IN THE FIXED BEDSTEAD DRIER WITH RADIAL DISTRIBUTION OF AIR}

\begin{abstract}
A study was conducted concerning the physiological quality of sorghum seed, variety BR 601, dried in a stationary perforated central tube type drier. Three heights combined with four distances in relation to the central duct were studied, completing a total of 12 treatments. It was observed that, in general, the samples siluated at $0.10 \mathrm{~m}$ from the hot air duct presented lower moisture grade than the general sample (control). When the quality of the seeds collected in distinct sites was compared with that of the general sample, no significant differences in the quality tests were verified, by the F test, at $5 \%$ probability level.
\end{abstract}

Key words: drying, quality, seeds

\section{INTRODUÇ̃̃O}

O sorgo (Sorghum sp.) é originário da África, mais precisamente da Eliópia e seu cultivo tem alcance mundial. Na
América Latina a cultura assumiu importância econômica após 1950 (House, 1979). Segundo Lira (1981) o sorgo chegou ao Brasil no século XVIII, com os escravos, embora se tenha tornado cultura comercial apenas a partir de 1980, quando atingiu

\footnotetext{
'MSc. Engenharia Agrícola, Doutorando em Engenharia Agrícola, bolsista da Capes, DEA-UFV, CEP 36571-000, Viçosa, MG

${ }^{2}$ Professor Titular, DEA-UJV, Fone 031-899-2134, Email: jadir@ dea.ufv.br, CEP 36571-000), Viçosa, MG

${ }^{3}$ Professor Adjunto, DEA-UFV, CEP 36571-000, Viçosa, MG

${ }^{4}$ Prol. Adjunta, DFT-UFV, CEP 35571-000, Viçosa, MG
} 
uma área plantada de 80.000ha; hoje, são plantados, no país, 314.000ha; por ordem de importância, é o quinto cereal do mundo depois do trigo, do arroz, do milho e da cevada (FAO, 1995) sendo um dos principais alimentos para milhões de habilantes das regiões semi-áridas da África, da Ásia e do Oriente Médio.

A secagem estacionária consiste basicamente em forçar o ar através de uma massa de sementes que permanece estática; requer, porém, condições especiais para o seu desempenho adequado. O secador estacionário, tipo tubo central perfurado, é um equipamento em que o ar é forçado a passar pelas sementes transversalmente (distribuição radial de ar) num tubo vertical perfurado, siluado na posição central do secador, desde a base até o topo. A câmara de secagem compreende o volume contido entre o tubo central e a parede externa do secador (Carvalho, 1994).

Uma limitação importante dos secadores de distribuição radial de ar é não permitir alterações na espessura da camada de sementes. Em geral, os produtores de sementes usam esse secador porque, além de ser de baixo custo, a secagem é estacionária evitando-se, assim, danos mecânicos, como aqueles causados pela contínua movimentação das sementes em outros tipos de secador. Sementes localizadas mais próximas do duto de ar quente são mais secas que aquelas que estão mais distantes e sua qualidade durante o armazenamento poderá ser inferior, dependendo da umidade com que o produto entra no secador. Os produtores de sementes não se preocupam com as diferenças de umidade entre sementes localizadas em pontos distintos do secador, promovendo a sua retirada quando a umidade média atinge o teor de umidade predeterminado para comercialização; além disso, é importante considerar que as sementes desses diferentes pontos podem apresentar diferenças quanto à qualidade fisiológica (Carvalho, 1994).

Considerando-se esses fatos, o presente trabalho teve por objetivos:

a) avaliar a uniformidade da secagem na massa de sementes secas em secador de camada fixa de distribuição radial de ar;

b) avaliar o efeito da secagem sobre a qualidade fisiológica das sementes de sorgo localizadas em diferentes pontos da massa, lanto no sentido radial quanto no longitudinal;

c) estabelecer um fator de qualidade que, por meio do somatório dos valores atingidos nos diversos testes de qualidade, permila identificar os melhores lotes de sementes.

\section{MATERIAL E MÉTODOS}

Nesta pesquisa foram utilizadas sementes de sorgo variedade BR 601, colhidas no período de 16 a 19 de setembro de 1996 , na Fazenda Florvel, no município de São Gonçalo do Abaeté, MG, e processadas na Unidade de Beneficiamento de Sementes da Empresa Sementes Ribeiral Ltda., localizada em Patos de Minas, MG.

\section{Coleta de amostras e caracterização do secador}

Foi utilizado um secador estático tipo tubo central perfurado, com capacidade de secagem de $8.000 \mathrm{~kg}$ de sementes; esse tipo de secador possui pontos de amostragens que permitem ao operador acompanhar a umidade do produto em vários locais. Coletaram-se amostras em três alturas distintas, 0,85, 2,02 e
$3,64 \mathrm{~m}$ da base do secador (Figura 1) e dentro de cada altura, em três distâncias diferentes, radialmente distribuídas. Foi utilizado um amostrador previamente preparado, de modo a permitir a coleta de sementes a $0,10 \mathrm{~m}$ (A), 0,30m (B) e $0,50 \mathrm{~m}$ (C) de distância do duto de ar quente do secador. Coletou-se também uma amostra-testemunha, média dos três pontos, para cada altura, fazendo-se opção por essas três alluras porque, na prática, somente nesses locais são coletadas amostras de sementes com o objetivo de se verificar o momento de parar de insuflar ar quente.

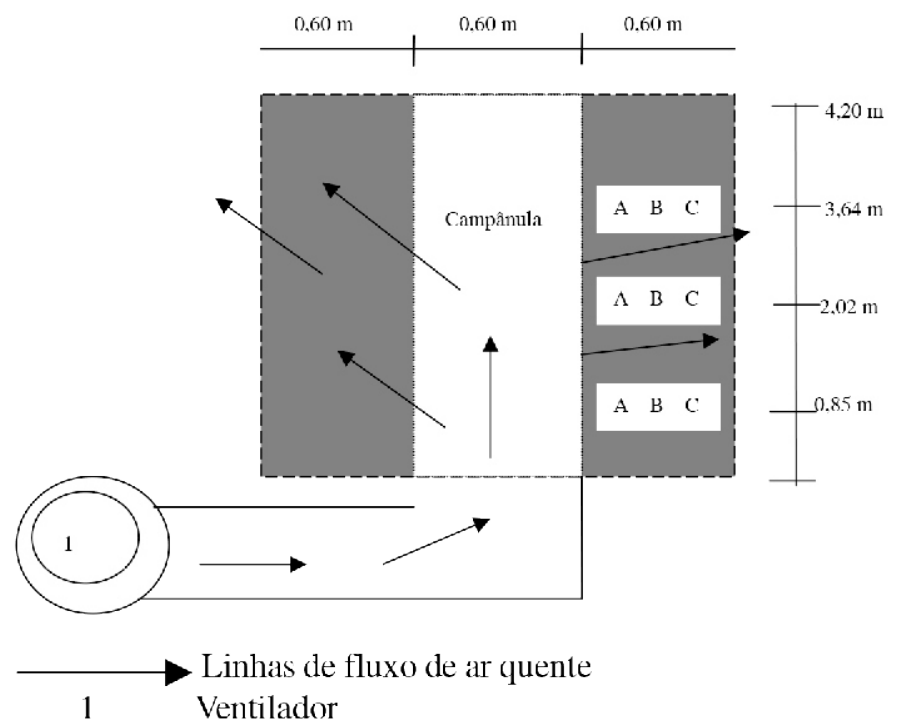

Figura 1. Corte transversal do secador mostrando os pontos de amostragem

Determinou-se o teor de umidade inicial das sementes (16\% em base úmida) o qual, durante a secagem, foi monitorado até chegar a $13 \%$, determinando-se o momento do final da secagem. Usou-se o sistema de aquecimento direto de ar com fluxo e temperatura do ar, respectivamente, de $14.000 \mathrm{~m}^{3} . \mathrm{h}^{-1}$ e $40^{\circ} \mathrm{C}$; o tempo de secagem por repetição foi de seis horas.

A temperatura da semente (ar intergranular) durante a secagem foi, em média, de $32^{\circ} \mathrm{C}$, não atingindo a temperatura do ar aquecido $\left(40^{\circ} \mathrm{C}\right)$; a razão dessa diferença de temperatura deveu-se ao fato de que parte do calor absorvido pelas sementes era para evaporar a água nelas contida (calor latente) enquanto a outra parte (calor sensível) foi responsável pelo aumento da temperatura das sementes; esta foi a razão de a temperatura do ar secante utilizado ter sido um pouco maior que aquela suportada pelas sementes, em níveis que não comprometeram a qualidade do produto final (Puzzi, 1986).

As sementes de sorgo, ao atingirem o teor de umidade de $13 \%$ em base úmida, foram resfriadas até a temperatura ambiente $\left(20^{\circ} \mathrm{C}\right)$ antes de serem armazenadas; esse resfriamento é necessário para evitar a formação de focos de aquecimento e reumedecimento do produto durante a armazenagem.

\section{Testes para avaliação da qualidade das sementes}

Três dias após a coleta as sementes de cada amostra foram submetidas aos seguintes testes: determinação do teor de umidade, teste-padrão de germinação, primeira contagem do teste de germinação, teste de envelhecimento acelerado, condulividade elétrica, teste de frio, emergência de plântulas em leito de areia, imersão em soluções tóxicas e fator de qualidade (FQ). 


\section{Determinação do teor de umidade das sementes}

Para determinação do teor de umidade, utilizou-se o métodopadrão da estufa a $105 \pm 3^{\circ} \mathrm{C}$, durante 24 horas, com quatro amostras, conforme recomendações contidas nas Regras para Análise de Sementes (Brasil, 1992) cujos resultados foram expressos em porcentagem e em base úmida.

\section{Teste padrão de germinação}

Foi realizado de acordo com as Regras para Análise de Sementes (Brasil, 1992) utilizando-se quatro amostras de 50 sementes. Usou-se como substrato rolo de papel-toalha tipo "germitest", umedecido com a quantidade de água equivalente a duas vezes e meia o peso do papel.

As sementes foram mantidas em germinador a temperatura constante de $25^{\circ} \mathrm{C}$. Foram efetuadas contagens do número de plântulas normais, anormais e mortas, sendo as contagens feitas nos quarlo e décimo dias após a semeadura (os resultados foram expressos em porcentagem média de plântulas normais).

\section{Testes de vigor (primeira contagem do teste de germinação)}

Conduzido juntamente com o teste-padrão de germinação, o teste de primeira contagem consistiu no registro da porcentagem de plântulas normais, constatada na data estabelecida para a primeira contagem, ou seja, no quarto dia após a montagem do teste de germinação; os resultados foram expressos em porcentagem média de plântulas normais.

\section{Teste de envelhecimento acelerado}

O envelhecimento acelerado foi conduzido segundo a metodologia da caixa "gerbox", descrita por Marcos Filho et al. (1987). As sementes foram distribuídas sobre a tela de aço, subdividida em quatro partes, e em cada parte foram colocados sete gramas de sementes, constituindo-se numa amostra.

As caixas "gerbox", contendo ao fundo $40 \mathrm{ml}$ de água destilada e a tela de aço com aproximadamente 850 sementes, foram vedadas com fita adesiva e colocadas numa câmara "Biological Organisms Development" (BOD) a temperatura de $42^{\circ} \mathrm{C}$ e a umidade relativa de $100 \%$, por 96 horas, conforme descreveram Marcos Filho et al. (1987).

Após esse período, quatro amostras de 50 sementes foram colocadas para germinar a temperatura de $25^{\circ} \mathrm{C}$, durante cinco dias, conforme descrito anteriormente; decorrido esse período, efetuou-se a interpretação, segundo Brasil (1992) quando foi avaliada a porcentagem de plântulas normais.

\section{Condutividade elétrica}

Após pesadas em balança de precisão $( \pm 0,01 \mathrm{~g})$ quatro amostras de 50 sementes foram colocadas dentro de copos plásticos (diâmetro de $6 \mathrm{~cm}$ ) contendo $75 \mathrm{ml}$ de água destilada; as sementes imersas permaneceram na BOD a $25^{\circ} \mathrm{C}$, durante 24 horas; decorrido esse período cada copo, contendo as sementes, foi agitado suavemente e mediu-se, então, a condutividade elétrica da solução, usando-se um condulivímetro. A média das condutividades foi expressa em $\mathrm{mS} . \mathrm{cm}^{1} \cdot \mathrm{g}^{1}$ de sementes, tomando-se as seguintes precauções: limpeza da célula do condutivímetro, após cada leitura, com água destilada, pesagem das sementes para eliminar possíveis diferenças de lamanho e determinação do teor de umidade inicial das sementes (Marcos Filho et al., 1987).

\section{Teste de frio}

Para execução do teste de frio foram utilizadas quatro amostras de 50 sementes, semeadas em papel "germitest" umedecido com quantidade de água equivalente a 2,5 vezes o peso desse papel seco. Em cada amostra foi feita a distribuição manual de pequena quantidade de solo umedecido, proveniente do local de onde o sorgo foi cultivado; após a semeadura, os rolos de papel foram introduzidos em sacos plásticos, vedados e colocados no interior de uma estufa (BOD) regulada para $10^{\circ} \mathrm{C}$, durante sete dias; após este período, foram retirados os sacos plásticos que envolviam as amostras, sendo estas transferidas para germinadores a $25^{\circ} \mathrm{C}$, onde permaneceram por cinco dias e cujos resultados foram expressos em porcentagem média de plântulas normais (Marcos Filho et al., 1987).

\section{Emergência de plântulas em leito de areia}

Foram semeadas, a $2 \mathrm{~cm}$ de profundidade, quatro amostras de 50 sementes de sorgo em bandejas contendo areia esterilizada e umedecida, as quais foram mantidas em casa de vegetação, no Departamento de Fitotecnia da UFV.

A velocidade de emergência foi determinada anotando-se o número de plântulas que emergiam diariamente, computadas a partir do quarto dia em que as sementes foram colocadas para germinar; posteriormente, determinou-se o índice de velocidade de emergência para cada amostra semeada, por meio do somatório do número de plântulas emergidas em cada dia dividido pelo número de dias decorridos entre a semeadura e a emergência, utilizando-se a seguinte fórmula, usada por Marcos Filho et al. (1987).

$$
\begin{aligned}
& \mathrm{k}
\end{aligned}
$$

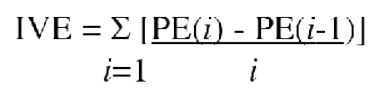

em que

IVE = índice de velocidade de emergência das sementes

$\mathrm{i}=$ dias decorridos entre a semeadura e a emergência da plântula

$\operatorname{PE}(i)=$ plântulas que emergiram no dia $i$

$\mathrm{PE}(i-1)=$ plântulas que emergiram no dia anterior ao dia $i$

$\mathrm{k} \quad=$ dia em que a emergência de plântulas se estabilizou

\section{Imersão em soluções tóxicas:}

Segundo orientação de Marcos Filho el al. (1987), quatro amostras de 50 sementes foram imersas em solução de cloreto de amônio $2 \%$, em copos plásticos, e colocadas em estufa com circulação de ar, a $40^{\circ} \mathrm{C}$, por 90 minutos; a seguir, foram lavadas em água corrente para eliminar o excesso de solução, e colocadas para germinar, conforme as Regras para Análise de Sementes; os resultados foram expressos computando-se a porcentagem de plântulas normais obtidas.

\section{Fator de qualidade}

Feitos os testes para avaliação da qualidade das sementes, determinou-se um fator de qualidade para cada amostra, da seguinte maneira: estabeleceu-se um valor teórico máximo de 500, que correspondia ao somatório de todos os resultados - exceto para o índice de velocidade de emergência e condutividade elétrica - obtidos nos cinco testes de qualidade feitos para cada amostra; as amostras foram classificadas, então, considerando-se a nola a elas atribuída, sendo considerada a de melhor qualidade aquela que obteve o maior somatório. 


\section{Delineamento experimental e análise dos dados}

Utilizou-se o modelo em parcelas subdivididas. As três alturas constituíram as parcelas dispostas no delineamento inteiramente casualizado, com quatro repetições; as quatro distâncias constituíram as subparcelas.

Utilizou-se o teste de Dunnet, a nível de $5 \%$ de probabilidade, para se comparar os resultados obtidos em cada ponto (distância do duto de ar quente) com aquele encontrado na amostra geral (testemunha)

\section{RESULTADOS E DISCUSSÃO}

\section{Teor de umidade}

Na Tabela 1 mostra-se que a umidade das sementes coletadas nos diversos locais do secador diferiu da umidade da amostra geral, em três pontos de amostragem. Dalpasquale et al. (1987) observaram que, se a camada de sementes for superior a $0,60 \mathrm{~m}$, a diferença de umidade entre as sementes próximas do duto de ar quente e aquelas mais distantes, pode chegar até a cinco pontos porcentuais de umidade. No presente trabalho, em que a espessura da camada foi de $0,60 \mathrm{~m}$, essa diferença não foi tão acentuada, porque se trabalhou com sementes de baixa umidade inicial (16\% em base úmida). Diferenças mais acentuadas provavelmente surgirão quando se obtiverem sementes com maior umidade inicial.

Tabela 1. Teor de umidade $(\%)$ de sementes de sorgo em razão de sua localização no secador

\begin{tabular}{|c|c|c|c|c|}
\hline \multirow[b]{2}{*}{ Nltura $^{b}(\mathrm{~m})$} & \multicolumn{3}{|c|}{ Distância $^{\text {a }}$ (m) } & \multirow[b]{2}{*}{$\Lambda G$} \\
\hline & 0,10 & 0,30 & 0,50 & \\
\hline 0,85 & 13,27 & 13,56 & $13,82^{\mathrm{C}}$ & 13,41 \\
\hline 2,02 & 13,21 & 13,32 & 13,67 & 13,48 \\
\hline 3,64 & $12,81^{\circ}$ & 13,49 & $13,69^{:}$ & 13,36 \\
\hline
\end{tabular}

Observou-se, também, tendência de sementes localizadas a $0,10 \mathrm{~m}$ do duto de ar quente apresentarem valores numéricos de teor de umidade inferiores ao da amostra geral; entretanto, esta diferença só foi significativa na altura de $3,64 \mathrm{~m}$; para sementes localizadas a $0,50 \mathrm{~m}$ do duto de ar quente, nas alturas de 0,85 e $3,64 \mathrm{~m}$, as médias de teor de umidade das sementes foram superiores às obtidas da amostra geral.

Essas verificações levaram à confirmação da hipótese de que esse tipo de secador promove uma secagem desuniforme das sementes. Com teores de umidades iniciais maiores que $20 \%$ em base úmida, as sementes secas na parte mais distante do duto central de ar quente apresentariam grande umidade final e, provavelmente, não poderiam ser armazenadas por muito tempo.

Verificou-se, como mostrado na Figura 2, que para a distância de $0,10 \mathrm{~m}$ do duto central de ar quente, a medida em que se coletavam amostras de sementes a maiores alturas, menores eram as umidades finais, isto é, havia um efeito quadrático e decrescente da altura na umidade; isso pode ser explicado porque a parte superior do secador, próxima ao duto de ar quente, era o caminho mais fácil para a saída do ar de secagem, pois a campânula, que regulava o fluxo, estava a $0,90 \mathrm{~m}$ da parte superior, fazendo com que o ponto de amostragem siluado a $3,64 \mathrm{~m}$ de altura e a $0,10 \mathrm{~m}$ do duto de ar quente, estivesse a $0,37 \mathrm{~m}$ do local da entrada de ar quente. Nas distâncias de 0,30 e $0,50 \mathrm{~m}$ e para a testemunha, não houve efeito de altura (Tabela 2).

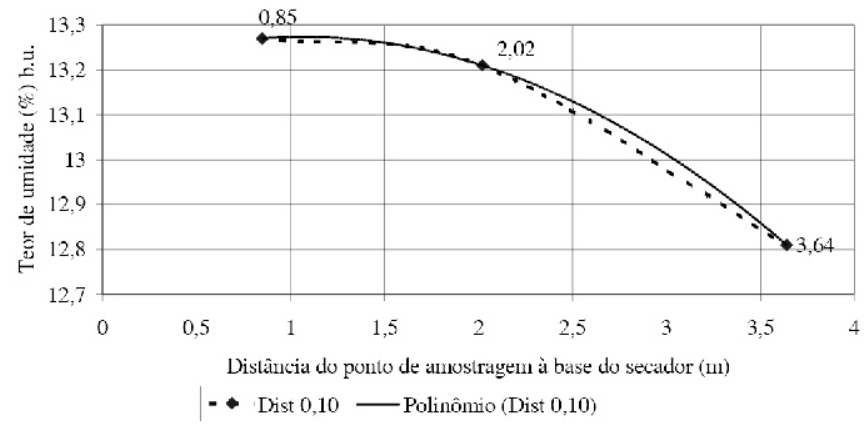

Figura 2. Teor de umidade das sementes de sorgo (Y) em razão da altura em relação à base do secador $(\mathrm{x})$ para a distância de $0,10 \mathrm{~m}$

Como a temperatura de secagem $\left(40^{\circ} \mathrm{C}\right)$ era a mais indicada para secagem de sementes e o seu tempo de permanência foi de seis horas, verificou-se que não houve supersecagem da camada de sementes próxima ao duto de ar quente $(0,10 \mathrm{~m})$. A espessura da camada de sementes e o teor de umidade inicial influenciaram a secagem de grãos e de sementes no secador estacionário. Dalpasquale et al. (1987) citaram que a espessura da camada de secagem deve estar entre 0,40 e $0,60 \mathrm{~m}$ e a temperatura de secagem tem de ser dependente da umidade do grão e/ou da semente, ou seja, quanto mais secos, maiores temperaturas de secagens admitem.

Tabela 2. Resumo da análise de variância do teor de umidade em sementes de sorgo em razão da altura nas diferentes distâncias do duto de ar quente

\begin{tabular}{lccccc}
\hline $\begin{array}{c}\text { lonte de } \\
\text { Variaçăo }\end{array}$ & $\begin{array}{c}\text { Graus de } \\
\text { liberdade }\end{array}$ & \multicolumn{5}{c}{$\begin{array}{c}\text { Quadrados médios } \\
\text { Distância (III) }\end{array}$} \\
\hline Linear & 1 & 0,10 & 0,30 & 0,50 & Testemunhlü \\
Quadrálico & 1 & 0,4232 & $0,0120 \mathrm{~ns}$ & $0,0276 \mathrm{~ns}$ & $0,0045 \mathrm{~ns}$ \\
Resíduo (a,b) & 29 & 0,0322 & $0,1080 \mathrm{~ns}$ & $0,0165 \mathrm{~ns}$ & $0,0247 \mathrm{~ns}$ \\
* Signilicativo, pelo teste F, a 5\% de probabilidade & & 0,0322 & 0,0322 & 0,0322 \\
\hline
\end{tabular}

is Nâu significalivo, pelo leste $\Gamma$, a $5 \%$ de probabilidate

Os resultados foram os esperados, pois as sementes estavam a $16 \%$ em base úmida ao darem entrada no secador e a temperatura de secagem usada foi a recomendada $\left(40^{\circ} \mathrm{C}\right)$.

\section{Avaliação da qualidade das sementes}

Na Tabela 3 encontra-se a análise de variância para os testes efetuados. Verificou-se que, com exceção do teste de frio, não houve efeito significativo das diferentes alturas nem da distância em relação ao duto central do secador sobre a qualidade das sementes.

$\mathrm{Na}$ Tabela 4 verifica-se que apenas sementes localizadas a $0,10 \mathrm{~m}$ do duto de ar quente apresentaram diferença significativa de qualidade no teste de frio em relação à amostra geral.

A manifestação do dano causado pela secagem sobre a qualidade das sementes pode resultar em efeitos imediatos e latentes. Os efeitos imediatos caracterizam-se pela redução da germinação e do vigor logo após a semente ter sido injuriada e podem ser verificados apenas pelo teste de frio, como mostrado neste trabalho. Os efeitos latentes não afetaram, de imediato, a viabilidade das sementes porém, após certo período de armazenamento, as sementes injuriadas sofreram reduções no poder germinativo e, também, no vigor, com reflexos negativos na sua potencialidade e na performance das sementes e das plantas no campo (Delouche, 1967). 
Tabela 3. Resumo da análise da variância dos valores obtidos nos diversos testes estudados

\begin{tabular}{|c|c|c|c|c|c|c|c|c|c|c|}
\hline \multirow[b]{3}{*}{$\begin{array}{l}\text { Fonte de } \\
\text { Variação }\end{array}$} & \multirow[b]{3}{*}{ GL } & \multicolumn{9}{|c|}{ Quadrados médios } \\
\hline & & \multicolumn{9}{|c|}{ Testes } \\
\hline & & $\begin{array}{c}\text { Teor de } \\
\text { Umidade }\end{array}$ & $\begin{array}{l}\text { Teste Padrão } \\
\text { de } \\
\text { Germinação } \\
\text { (TPG) }\end{array}$ & $\begin{array}{c}\text { Primeira } \\
\text { contagem do } \\
\text { TPG }\end{array}$ & $\begin{array}{c}\text { Envelheci } \\
\text { mento } \\
\text { acelerado }\end{array}$ & $\begin{array}{l}\text { Conduli- } \\
\text { vidade } \\
\text { elétrica }\end{array}$ & $\begin{array}{l}\text { Teste de } \\
\text { frio }\end{array}$ & $\begin{array}{c}\text { Índice de } \\
\text { velocidade de } \\
\text { emergência }\end{array}$ & $\begin{array}{c}\text { Imersão } \\
\text { em clorelo } \\
\text { de amônio }\end{array}$ & $\begin{array}{c}\text { Fator de } \\
\text { qualidade }\end{array}$ \\
\hline Altura (A) & 2 & $0,1234 n s$ & $8,1132 \mathrm{~ns}$ & $2,0989 \mathrm{~ns}$ & $9,1497 \mathrm{~ns}$ & $0,7060 \mathrm{~ns}$ & $44,7343 \mathrm{~ns}$ & $28,1280 \mathrm{~ns}$ & $2,8945 \mathrm{~ns}$ & $29,0838 \mathrm{~ns}$ \\
\hline Resíduo(A) & 9 & 0,0550 & 14,1488 & 41,4131 & 15,3467 & 2,3771 & 55,7226 & 20,1162 & 9,1662 & 524,6507 \\
\hline $\operatorname{Dist}(\mathrm{D})$ & 3 & $0,7977 \mathrm{~ns}$ & $6,0881 \mathrm{~ns}$ & 6,1388 & $5,3276 \mathrm{~ns}$ & $1,1786 \mathrm{~ns}$ & $72,0915^{*}$ & $4,5136 \mathrm{~ns}$ & $0,3971 \mathrm{~ns}$ & $165,9140 \mathrm{~ns}$ \\
\hline DxA & 6 & $0,0772 \mathrm{~ns}$ & $12,5334 \mathrm{~ns}$ & $11,1336 \mathrm{~ns}$ & $12,8563 \mathrm{~ns}$ & $2,1204 \mathrm{~ns}$ & $43,4027 \mathrm{~ns}$ & $11,3067 \mathrm{~ns}$ & $5,0507 \mathrm{~ns}$ & $175,5741 \mathrm{~ns}$ \\
\hline Resíduo(B) & 27 & 0,0246 & 6,5979 & 15,5659 & 10,2426 & 4,1004 & 23,2238 & 6,3960 & 4,7958 & 130,6770 \\
\hline
\end{tabular}

* Significativo, a $5 \%$ de probabilidade, pelo teste F

ns Nao significativo, a $5 \%$ de probabilidade, pelo teste $F$

Tabela 4. Resultados médios dos testes de qualidade obtidos para sementes localizadas nas diferentes distâncias do duto central de ar quente, em comparação com os da amostra geral

\begin{tabular}{lccrl}
\hline & \multicolumn{4}{c}{ Distância ao Duto de Ar Qucntc } \\
\cline { 2 - 5 } Teste $^{1}$ & $0,10 \mathrm{ml}$ & $0,30 \mathrm{~m}$ & $0,50 \mathrm{nI}$ & \multicolumn{1}{c}{ (G } \\
\hline TPG & $91,62 \mathrm{~ns}$ & $90,95 \mathrm{~ns}$ & $90,37 \mathrm{~ns}$ & 91,97 \\
PCT & $86,58 \mathrm{~ns}$ & $86,49 \mathrm{~ns}$ & $85,66 \mathrm{~ns}$ & 87,41 \\
EACEL & $86,04 \mathrm{~ns}$ & $87,10 \mathrm{~ns}$ & $86,93 \mathrm{~ns}$ & 87,64 \\
COND & $89,74 \mathrm{~ns}$ & $90,12 \mathrm{~ns}$ & $90,27 \mathrm{~ns}$ & 90,45 \\
THRIO & $76,41 * *$ & $79,27 \mathrm{~ns}$ & $80,16 \mathrm{~ns}$ & 82,33 \\
IVE & $87,46 \mathrm{~ns}$ & $85,84 \mathrm{~ns}$ & $86,87 \mathrm{~ns}$ & 86,25 \\
IME & $89,03 \mathrm{~ns}$ & $89,12 \mathrm{~ns}$ & $89,29 \mathrm{~ns}$ & 88,85 \\
FQ & $429,24 \mathrm{~ns}$ & $433,13 \mathrm{~ns}$ & $432,43 \mathrm{~ns}$ & 438,59
\end{tabular}

${ }^{1}$ TPG-teste padrăo de germinaç⿰丿; PCT-primeira contagem do teste de germinaç⿰o; FACFI -envelhecimento a elerado; COND-condutividade elétrica; TFRIO-test do frio; IVF-indice de velocidade de cimento arelerado; COND-condutuvidade elétrica; TFRTO-test do frio;
emergência: TMF-imersão em soluçăo tóxica; FQ-fator de qualidade.

*** Difere signilicativamente a $5 \%$ de probabilidade, pelo teste de Dunnet, $\mathrm{cm}$ relaçào à amostra geral

us Nào difere siguilieativamente a $5 \%$ de probabilidade, pelo teste de Duunet, em relaçào à amostra geral

Para secagem de sementes, a qualidade do produto final adquire maior relevância não só quanto à minimização das danificações mecânicas durante a secagem mas, principalmente, quanto à manutenção da qualidade fisiológica por períodos prolongados. As sementes analisadas em setembro de 1996 apresentaram excelente qualidade para armazenamento.

\section{CONCLUSÕES}

Os resultados experimentais permitiram concluir que:

1. A secagem das sementes não foi uniforme, ou seja, houve diferença significativa no teor de umidade final de sementes localizadas a $0,10 \mathrm{~m}$ de distância do duto central na altura de $3,64 \mathrm{~m}$ e, também, no teor de umidade das sementes localizadas a $0,50 \mathrm{~m}$ de distância desse duto, nas alturas de 0,85 e $3,64 \mathrm{~m}$ da base do secador.

2. O efeito da secagem sobre a qualidade fisiológica das sementes de sorgo localizadas em diferentes pontos da massa, tanto no sentido radial quanto no longitudinal, não foi significativo.

3. O fator de qualidade estabelecido não permiliu identificar as diferenças de qualidade entre os lotes de sementes estudados.

\section{REFERÊNCIAS BIBLIGRÁFICAS}

BRASIL. Ministério da Agricultura e Reforma Agrária. Regras para análise de sementes Brasília, DF: 1992. 365p.

CARVALHO, N.M. A secagem de sementes. Jaboticabal, SP: FUNEP, 1994. 165p.

DALPASQUALE, V.A.; QUEIROZ, D.M.; PEREIRA, J.A.M. Secagem de grãos em altas temperaturas. Viçosa, $M G$ : CENTREINAR, 1987. 47p.

DELOUCHE, J.C. Mechanical damage to seed. In: SHORT COURSE FOR SEEDSMEN, Mississippi State, 1967. Proceedings...S.1.: Mississippi State University, 1967. p. $65-$ 71.

FAO. Production Yearbook, Roma, v.8, n.1, p. 19-28, 1995.

HOUSE, L.R. A guide to sorghum breeding. Hyderabad, Índia: ICRISAT, 1979. 238p. (International Crops Research Institute for the Semi-Arid Tropics).

LIRA, M.A. Considerações sobre o potencial do sorgo em Pernambuco. In: CURSO DE EXTENSÃO SOBRE A CULTURA DO SORGO, 1980, Vitória de Santo Antão, PE. Curso de Extensão. Brasília DF: EMBRAPA, DID, 1981. p. 87-88 (Documento 1).

MARCOS FILHO, J.; CÍCERO, S.M.; SILVA, W.R. Avaliação da qualidade de sementes. Piracicaba, SP: ESALQ, 1987. $230 \mathrm{p}$.

PUZZI, D. Abastecimento e armazenagem de grãos. Campinas, SP: Instituto Campineiro de Ensino Agrícola, 1986. 603p. 